\title{
Negative latent tuberculosis at time of incarceration: identifying a very high-risk group for infection
}

\author{
L. ARROYAVE ${ }^{1}, Y$. KEYNAN ${ }^{2}$, L. LÓPEZ ${ }^{3}$, D. MARIN ${ }^{3}$, M. P. ARBELÁEZ ${ }^{1}$ AND \\ Z. V. RUEDA ${ }^{3,4 *}$ \\ ${ }^{1}$ Facultad Nacional de Salud Pública, Universidad de Antioquia UdeA, Medellín, Colombia \\ ${ }^{2}$ Department of Internal Medicine, Medical Microbiology and Community Health Sciences, University of \\ Manitoba, Winnipeg, Canada \\ ${ }^{3}$ Facultad de Medicina, Universidad Pontificia Bolivariana, Medellín, Colombia \\ ${ }^{4}$ Department of Medical Microbiology, University of Manitoba, Winnipeg, Canada
}

Received 27 January 2017; Final revision 31 May 2017; Accepted 3 July 2017; first published online 31 July 2017

\section{SUMMARY}

The main aim was to measure the incidence of latent tuberculosis infection (LTBI) and identify risk factors associated with infection. In addition, we determined the number needed to screen (NNS) to identify LTBI and active tuberculosis. We followed 129 prisoners for 2 years following a negative two-step tuberculin skin test (TST). The cumulative incidence of TST conversion over 2 years was $29 \cdot 5 \%$ (38/129), among the new TST converters, nine developed active TB. Among persons with no evidence of LTBI, the NNS to identify a LTBI case was 3.4 and an active TB case was 14.3. The adjusted risk factors for LTBI conversion were incarceration in prison number 1 , being formerly incarcerated, and overweight. In conclusion, prisoners have higher risk of LTBI acquisition compared with high-risk groups, such as HIV-infected individuals and children for whom LTBI testing should be performed according to World Health Organization guidance. The high conversion rate is associated with high incidence of active TB disease, and therefore we recommend mandatory LTBI screening at the time of prison entry. Individuals with a negative TST at the time of entry to prison are at high risk of acquiring infection, and should therefore be followed in order to detect convertors and offer LTBI treatment. This approach has a very low NNS for each identified case, and it can be utilized to decrease development of active TB disease and transmission.

Key words: Incidence, latent tuberculosis, prisons, risk factors, tuberculin test.

\section{INTRODUCTION}

Incarceration is a recognized risk factor for tuberculosis (TB) infection. The median estimated annual incidence rate ratio for latent tuberculosis infection (LTBI) in five prisons in the USA and one in Brazil

\footnotetext{
* Author for correspondence: Z. V. Rueda, Escuela de Ciencias de la Salud, Universidad Pontificia Bolivariana, Calle 78B No. 72A-109, Medellín, Colombia (E-mail: zulmaruedav@gmail.com)
}

was $26 \cdot 4$ (interquartile range (IQR) $13 \cdot 0-61 \cdot 8$ ) compared with the general population [1].

Rangaka et al. and World Health Organization (WHO) highlighted in 2015 that if elimination of TB is desired, containment of the reservoirs, or seedbeds, of infection is essential [2].

In order to identify most at-risk groups and prioritize LTBI testing in a way that is feasible, WHO divided conditions predisposing to active TB into three categories [3], for systematic testing and 
treatment of LTBI: high-risk group, where screening is deemed necessary; a medium-risk group, where screening should be considered; and a low-risk group, for whom LTBI screening is not recommended. Individuals in prisons are included in the second, medium-risk group. The limitation of the recommendations stems from the low to very low quality of evidence they are based upon [3].

Active TB in prisons has been shown to be 22 -fold higher than the levels seen in the corresponding general population [1,4]. The high incidence of active disease is likely multi-factorial and can be attributed to co-existence of multiple risk factors as a result belonging to population groups already at high risk of TB infection and TB disease (e.g. low socio-economic strata, alcohol or drug users, homeless people, nutritionally deficient, mentally ill individuals, former prisoners, and immigrants from areas with high TB burden) [5]. The prison setting serves as an accelerator by adding overcrowding, and confined space that further augment the risk of transmission [1,6,7]. The high turnover rates of prisoners, inadequate access to diagnostic microbiology and imaging and difficulties in implementing adequate infection control standards contribute to transmission of Mycobacterium tuberculosis. For example, in a previous study from two prisons in Colombia, we reported prevalence of tuberculin skin test (TST) positivity of $77.6 \%$ in densely populated prisons, a LTBI prevalence significantly higher than the general population [8].

An early diagnosis of LTBI is important in order to initiate treatment of LTBI, and consequently, reduce the risk of developing active TB. This approach provides benefits to both infected and susceptible inmates inside prisons. The incidence of recent conversion of TST reported in Maryland prisons was $6 \cdot 3$ per 100 person-years, and the use of broader coverage levels of isoniazid prophylaxis reduced the risk of infection by $50 \%$ [9].

Currently, available regimens for the treatment of LTBI have an efficacy ranging from $60 \%$ to $90 \%$, the protection of which can last for up to 19 years [3]. For infected individuals in population groups with a high risk of progression to active disease, the anticipated benefits are usually greater than the potential harms (such as drug related hepatotoxicity, etc.), and incarceration provides an opportunity for provision of observed therapy increasing the chance for completion in a relatively young population that is less likely to access healthcare otherwise. It is thus important to identify which groups would benefit most [10]. The 2015 WHO guidelines on the management of LTBI highlight that one of the priority research gaps is to "measure the risk of progression from LTBI to active disease in a number of risk groups is crucial to determine the potential benefits of LTBI treatment and design appropriate public health interventions' [4].

In this cohort study, we focused on the individuals with no evidence of LTBI at the time of initial testing in order to assess the risk of transmission within the prison, as they represent highly susceptible individuals in a high incidence setting for active TB (500 cases/ $100000)$ [11]. To address this gap in the context of high prevalence setting of a Colombian prison, we determined the rate of TST conversion among inmates with a negative test upon initial screening, and the rate of active TB diagnosis among those TST negative, and investigated the risk factors associated with the incidence of LTBI.

\section{METHODS}

\section{Population}

One hundred and eighty-six prisoners followed in the previous study were enrolled for the current cohort [8]. Their follow-up started after initial negative TST twostep applications as previously described on November 2012 to December 2013 [8], and continued for up to 2 years to determine the incidence of LTBI, between February and April 2015.

\section{Inclusion criteria}

Individuals who had TST two-step administration, who voluntarily agreed to participate in the study and signed the consent form.

\section{Exclusion criteria}

Exclusion criteria were: (1) administration of live vaccines in the 4 weeks before TST administration, (2) severe adverse event with a previous TST administration, (3) previous active TB, and (4) people who were no longer incarcerated in prison (liberated or moved into house detention) living outside of Medellin or Itagüí because of the impossibility to follow-up.

\section{Study setting}

The study took place in two male prisons in Medellin (Establecimiento Penitenciario y Carcelario de Mediana 
Seguridad de Medellín) and Itagui (Establecimiento Penitenciario y Carcelario La Paz). Prison 1 (P1) in Medellin has a population of 5761 (capacity: 2008, overcrowding of $187 \%$ above capacity), and prison 2 (P2) in Itagui has 1014 prisoners (capacity: 328, overcrowding of $209 \%$ above capacity). The capacity of the $\mathrm{P} 1$ changed compared with our previous publication, due to renovations and temporary closure of one of the wings with transfer of prisoners to other facilities. The active TB incidence in P1 ranged between 505/100000 [11] in 2012 and 920 per 100000 in 2016. The TB incidence in P2 ranged from 591 cases per 100000 in 2015 to zero cases in 2016.

In $\mathrm{P} 1$, active TB cases are isolated in a separate infirmary area with five rooms of up to 2-6 individuals per room. In P2, there is a single isolation room accommodating up to two individuals.

LTBI screening is not routinely performed nor is LTBI treatment offered by health administration in these prisons. All tests have been performed in the context of this research project. Our group provides TB education to prison administrators and inmates and regularly participates in health authority committee. We continue to advocate for implementation of routine LTBI screening and treatment. Our efforts contributed to active TB case finding and we endeavor to highlight the importance of LTBI.

\section{Procedures}

Two years after the recruitment to original observational cohort, a third TST was administered according to Centers for Diseases Control and Prevention recommendations. Reading was performed by experienced research nurses 48 or $72 \mathrm{~h}$ after TST administration and measured in millimeters $(\mathrm{mm})$ induration.

The main outcome was the TST conversion defined as an induration of $\geqslant 10 \mathrm{~mm}$ diameter with a difference of at least $\geqslant 6 \mathrm{~mm}$ diameter between the second (booster application) and third administration [12].

People who were no longer incarcerated in prison (liberated or moved into house detention) at the time of the third TST were contacted by phone to request the participation in follow-up that would be conducted according to their preference, either at home, at the work place, or in our university.

We did not test for HIV because in a previous study we estimated that the prevalence of HIV was $2 \cdot 1 \%$ (26/ $1238)$ overall, and $4 \cdot 2 \%(3 / 72)$ among individuals with active TB [11].

\section{Follow-up}

All prisoners were assessed for the presence of symptomatic TB. Presence of lower respiratory symptoms, defined as a cough of any duration and/or expectoration, and abnormal breath sounds on lung auscultation triggered further study and collection of smear and culture. Sputum samples were obtained and processed by health authorities. This protocol was followed for the duration of the study irrespective of TST result (for both TST+ and TST - with the above symptoms).

We also studied all converters to rule out active TB between May to October 2015 by state health authorities using sputum (spontaneous or induced according to sputum production) acid-fast smear, culture and GeneXpert, and chest X-rays. The presence of active TB was recorded for all participants.

Finally, for those prisoners that were released or transferred to another prison, we verified in the mandatory notification system (SIVIGILA) if any of that prisoner was diagnosed with active TB.

\section{Analysis}

We determined the incidence of positive TST in prisoners. To elucidate the factors associated with a positive TST result, we performed a bivariate analysis, estimating the relative risk (RR) and the 95\% confidence interval (CI). Any of the variables that attained a $P<0.25$, as well as the presence of bacillus Calmette-Guérin vaccine (BCG) scar were included in a binomial regression. The RR and 95\% CIs are reported and adjusted for age, prior incarceration, time of actual incarceration, contact with a TB case before TST administration, and BCG scar, factors previously reported to be associated with TB infection. As we found in a previous study that the two prisons differed markedly in the prevalence of positive TST, the standard errors for bivariate and multivariate analysis were adjusted by the cluster effect for each prison. The numbers needed to screen (NNS) in order to detect one LTBI case and active TB cases were estimated in those who were screened with TST. Analysis was performed using STATA ${ }^{\circledR}$ version 11.0 and SPSS $^{\circledR}$ version 20.0 software.

\section{RESULTS}

Among 129 prisoners that we could follow and who were TST negative at the outset, the incidence of TST conversion over 2 years was 29.5\% (38/129) (Fig. 1). 


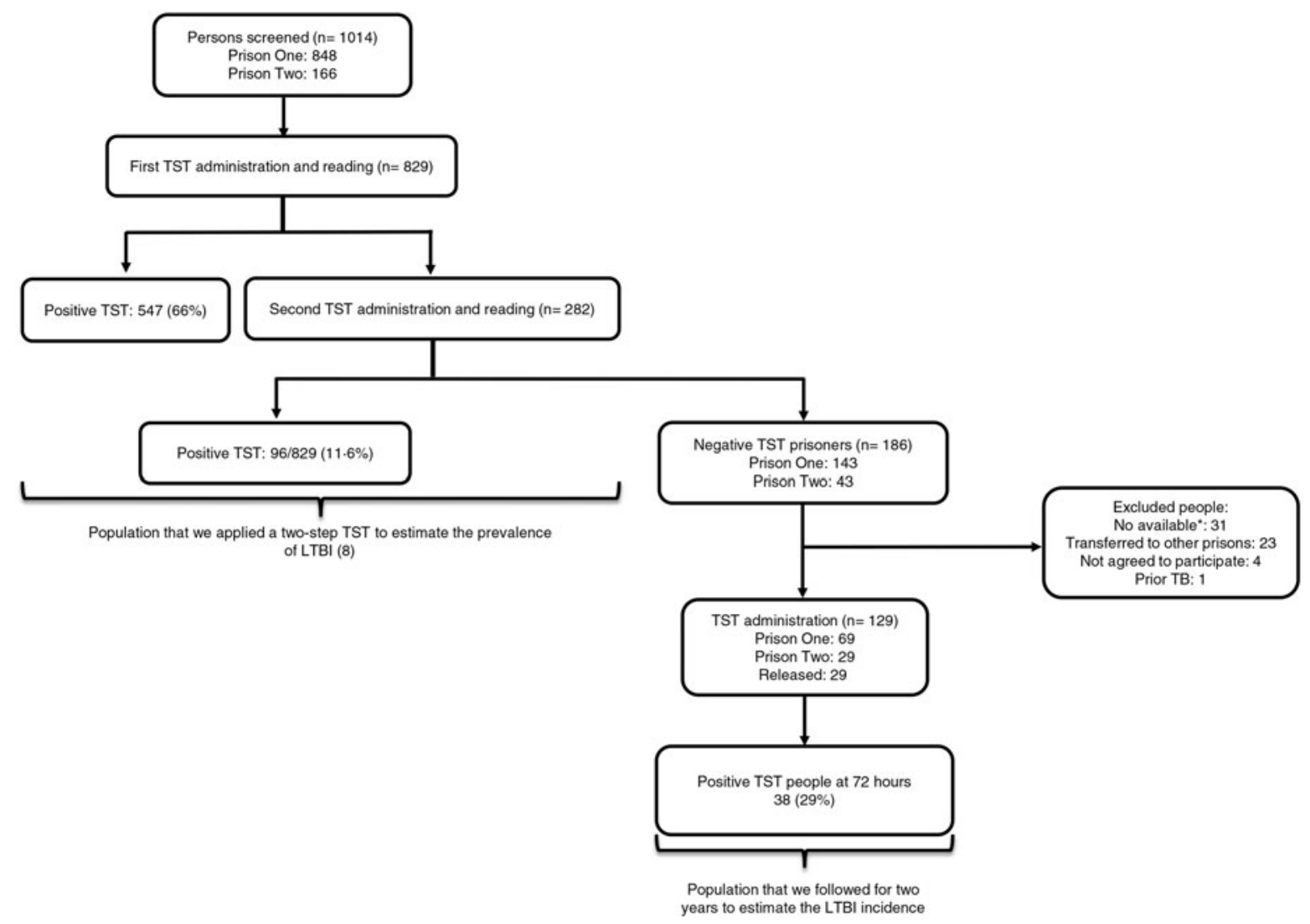

Fig. 1. Flowchart of people included in the study. The prevalence of LTBI was published before [8]. *Not available used to designate individuals that were absent due to legal procedure (court subpoena, etc.).

Forty-one percent (53/129) of people had a prior contact with a TB case (outside or inside prison), among them $77 \%(41 / 53)$ of the contacts were with a prisoner. After 2 years of follow-up, 22\% (29/129) were released from prison. The median time spent in incarceration was 26 months for those released (IQR 21-45 months) (Table 1).

The risk factors associated with LTBI acquisition were incarceration in P1, being formerly incarcerated, and overweight (body mass index $\geqslant 25 \mathrm{~kg} / \mathrm{m}^{2}$ ) (Table 2).

Ten individuals developed active TB during follow-up among $129(8 \%)$, of these nine were new TST converters (four by culture, four by GeneXpert, and one by smear), (Incidence TB rate: 6976/100 000). All nine individuals were asymptomatic at the time of TST application, and active TB was diagnosed 5-8 months after the documented conversion. An additional person developed active TB at month 16 after an initial negative TST and prior to the third TST administration. Because we do not know if this person was a new converter or TST negative, we included nine individuals for all estimations. All prisoners diagnosed with active TB received anti-tuberculous therapy.

The NNS to detect a new LTBI case for 2 years was $3 \cdot 4$ (129/38), and the NNS to detect an active TB case among TST converters was $14 \cdot 3$ (129/9).

\section{DISCUSSION}

In this study, we performed a prospective follow-up on a previous cohort in two Colombian prisons, in which we documented very high LTBI prevalence $(77 \cdot 6 \%)$ at the time of initial TST [8]. We hypothesized that this population may be at high risk and require prioritizing for follow-up and treatment. We therefore followed this group of susceptible inmates with an initial negative TST in order to determine the rates of TST conversion and the rate of active TB diagnosis over 2 years. Individuals with a negative test upon initial screening accounted for less than a quarter of inmates, and of 129 individuals with negative TST at the time of incarceration, 38 developed a reactive TST within 2 years of follow-up representing 29\% (annual risk of $14.5 \%$ ) for TST conversion. This annual risk of 
Table 1. Characteristics of prisoners with new latent tuberculosis infection compared with those who did not convert in two prisons in Colombia, 2013-2015

\begin{tabular}{|c|c|c|c|c|c|c|}
\hline \multirow[b]{3}{*}{ Variables } & \multicolumn{6}{|c|}{ Incidence of LTBI } \\
\hline & \multicolumn{2}{|c|}{$\begin{array}{l}\text { Positive } \\
N=38\end{array}$} & \multicolumn{2}{|c|}{$\begin{array}{l}\text { Negative } \\
N=91\end{array}$} & \multicolumn{2}{|c|}{$\begin{array}{l}\text { Total } \\
N=129\end{array}$} \\
\hline & $N$ & $\%$ & $n$ & $\%$ & $n$ & $\%$ \\
\hline \multicolumn{7}{|l|}{ Age } \\
\hline$>35$ years & 12 & $25 \cdot 0$ & 36 & $75 \cdot 0$ & 48 & 100 \\
\hline$\leqslant 35$ years & 26 & $32 \cdot 1$ & 55 & $67 \cdot 9$ & 81 & 100 \\
\hline \multicolumn{7}{|l|}{ Contact with a TB case } \\
\hline Never & 23 & $30 \cdot 3$ & 53 & $69 \cdot 7$ & 76 & 100 \\
\hline Before last year & 8 & $22 \cdot 9$ & 27 & $77 \cdot 1$ & 35 & 100 \\
\hline Last year & 7 & $38 \cdot 9$ & 11 & $61 \cdot 1$ & 18 & 100 \\
\hline \multicolumn{7}{|c|}{$\begin{array}{l}\text { Who was the TB contact prior } \\
\text { to TST administration }\end{array}$} \\
\hline Prisoner & 15 & $36 \cdot 6$ & 26 & $63 \cdot 4$ & 41 & 100 \\
\hline Family & 0 & $0 \cdot 0$ & 5 & $100 \cdot 0$ & 5 & 100 \\
\hline Other & 0 & $0 \cdot 0$ & 7 & $100 \cdot 0$ & 7 & 100 \\
\hline \multicolumn{7}{|c|}{$\begin{array}{l}\text { Place where the person was } \\
\text { after } 2 \text { years of follow-up }\end{array}$} \\
\hline Prison 1 & 25 & $35 \cdot 2$ & 46 & $64 \cdot 8$ & 71 & 100 \\
\hline Prison 2 & 1 & $3 \cdot 4$ & 28 & $96 \cdot 6$ & 29 & 100 \\
\hline $\begin{array}{c}\text { Being formerly } \\
\text { incarcerated }\end{array}$ & $12^{*}$ & $41 \cdot 4$ & 17 & $58 \cdot 6$ & 29 & 100 \\
\hline \multicolumn{7}{|l|}{ Smoking status } \\
\hline No & 19 & $25 \cdot 7$ & 55 & $74 \cdot 3$ & 74 & 100 \\
\hline Last month & 18 & $35 \cdot 3$ & 33 & $64 \cdot 7$ & 51 & 100 \\
\hline Last year & 1 & $25 \cdot 0$ & 3 & $75 \cdot 0$ & 4 & 100 \\
\hline \multicolumn{7}{|l|}{ Place of sleeping } \\
\hline Other & 19 & $46 \cdot 3$ & 22 & $53 \cdot 7$ & 41 & 100 \\
\hline Cell & 19 & $21 \cdot 6$ & 69 & $78 \cdot 4$ & 88 & 100 \\
\hline \multicolumn{7}{|l|}{ Nutritional status } \\
\hline Normal & 22 & $27 \cdot 8$ & 57 & $72 \cdot 2$ & 79 & 100 \\
\hline Overweight ${ }^{\dagger}$ & 16 & $32 \cdot 0$ & 34 & $68 \cdot 0$ & 50 & 100 \\
\hline Presence of BCG scar & 21 & $26 \cdot 9$ & 57 & $73 \cdot 1$ & 78 & 100 \\
\hline \multicolumn{7}{|c|}{ Total time of incarceration } \\
\hline$<36$ months & 24 & $37 \cdot 5$ & 40 & $62 \cdot 5$ & 64 & 100 \\
\hline$\geqslant 36$ months & 14 & $22 \cdot 6$ & 48 & $77 \cdot 4$ & 62 & 100 \\
\hline \multicolumn{7}{|l|}{ Prior incarceration } \\
\hline Yes & 6 & $23 \cdot 1$ & 48 & $76 \cdot 9$ & 54 & 100 \\
\hline No & 24 & $30 \cdot 8$ & 40 & $69 \cdot 2$ & 64 & 100 \\
\hline
\end{tabular}

LTBI, latent tuberculosis infection; TST, tuberculin skin test; BCG, bacillus Calmette-Guérin vaccine.

* All positive TST converters were incarcerated in prison 1. $\dagger$ Body mass index $\geqslant 25 \mathrm{~kg} / \mathrm{m}^{2}$.

tuberculous infection (ARTI) in prisoners was higher than the median estimated ARTI reported among healthcare workers [between 2.9\% (IQR 1.8\%-8.2\%) and $8.7 \%$ (IQR $3 \cdot 9 \%-10 \cdot 5 \%$ )] [13], and the ARTI in children (between $0.8 \%$ and $4 \cdot 2 \%$ ) depending on the method and the setting's TB incidence rate [14-16].
The prevalence of LTBI reported in high-risk groups for whom systematic testing and treatment of LTBI is recommended [3] ranges between $3 \cdot 5 \%$ and $76 \%$ [17,18], and the TB incidence rates between $4 \cdot 89$ and $14 \cdot 1$ per 1000 person-years [19,20], and an annual conversion of $2.8 \%$ in patients with dialysis [21]. In the medium-risk group, the prevalence of LTBI ranges between $33 \%$ and $87 \cdot 6 \%$ [1,8,22,23], and the TB incidence rates between 9 and 5780 per 100000 in healthcare workers [22], to 61 and 6799 per 100000 in prisoners [1]. Among low-risk group, the prevalence of LTBI ranges between $28.2 \%$ and $51 \cdot 3 \%$ [24,25], and the incidence of TB was $16 \cdot 2$ cases per 100000 person-years in patients with diabetes [26].

Despite the high risk, the WHO guidelines [3] published in 2015 grade the need for screening for LTBI in prisoners at the intermediate level 'should be considered' instead of the 'should be performed' recommendation, reserved for the highest risk groups.

Moreover, 9/38 TST converters developed active disease within the follow-up period, indicating they represent an extremely high-risk group for not only acquisition of $M$. tuberculosis but also for progression to active disease, highlighting the need for screening. If a LTBI screening is to be implemented at entry to prison, follow-up of both positive and negative to TST is required. Individuals with risk factors for TB but without respiratory symptoms should be re-evaluated if respiratory symptoms develop. TST negative prisoners require follow-up every year in order to identify early converters, thus creating an opportunity for LTBI treatment and prevention of onward transmission. High priority for recent LTBI converters with targeted questioning, examination, radiography, and sputum studies may be warranted.

The high incidence of LTBI in prisons results in high costs of microbiology and radiographic screening among this vast population. In resource-limited setting, follow-up and management of all LTBI is rarely feasible, hence frequently not attempted [27]. The individuals with non-reactive TST are susceptible to M. tuberculosis acquisition and represent sentinels for TB transmission in prisons. The high rate of TST conversion representing recent $M$. tuberculosis acquisition resulted in a very low NNS in order to detect a LTBI case of 3.4 in those people with an initially negative TST. Because of the converging risk factors for progression to active TB among prisoners, the NNS to detect an active TB case was also very low at $14 \cdot 3$. In the WHO systematic review, the NNS in 
Table 2. Risk factors associated with the incidence of latent tuberculosis infection in prisoners over 2 years of follow-up in two prisons in Colombia, 2013-2015

\begin{tabular}{|c|c|c|c|c|c|c|}
\hline \multirow[b]{2}{*}{ Variable } & \multirow[b]{2}{*}{$\begin{array}{l}\text { Crude } \\
\text { relative risk }\end{array}$} & \multicolumn{2}{|c|}{$\begin{array}{l}95 \% \text { confidence } \\
\text { interval }\end{array}$} & \multirow[b]{2}{*}{$\begin{array}{l}\text { Adjusted } \\
\text { relative risk }\end{array}$} & \multicolumn{2}{|c|}{$\begin{array}{l}95 \% \text { confidence } \\
\text { interval }\end{array}$} \\
\hline & & $\begin{array}{l}\text { Lower } \\
\text { limit }\end{array}$ & $\begin{array}{l}\text { Upper } \\
\text { limit }\end{array}$ & & $\begin{array}{l}\text { Lower } \\
\text { limit }\end{array}$ & $\begin{array}{l}\text { Upper } \\
\text { limit }\end{array}$ \\
\hline No contact & $1 \cdot 00$ & - & - & $1 \cdot 00$ & - & - \\
\hline $\begin{array}{l}\text { Contact with a prisoner with TB } \\
\text { prior to TST administration }\end{array}$ & $0 \cdot 94$ & $0 \cdot 85$ & $1 \cdot 03$ & $0 \cdot 53$ & $0 \cdot 27$ & $1 \cdot 03$ \\
\hline No BCG scar & $1 \cdot 00$ & - & - & $1 \cdot 00$ & - & - \\
\hline BCG scar & $0 \cdot 89$ & $0 \cdot 83$ & $0 \cdot 96$ & $0 \cdot 96$ & $0 \cdot 60$ & $1 \cdot 55$ \\
\hline Prison 2 & $1 \cdot 00$ & - & - & $1 \cdot 00$ & - & - \\
\hline Prison 1 & $10 \cdot 2$ & $9 \cdot 14$ & $11 \cdot 4$ & $11 \cdot 66$ & $1 \cdot 65$ & $82 \cdot 18$ \\
\hline Being formerly incarcerated & $12 *$ & $10 \cdot 48$ & $13 \cdot 74$ & $17 \cdot 27$ & $2 \cdot 44$ & $121 \cdot 94$ \\
\hline No smoking & $1 \cdot 00$ & - & - & $1 \cdot 00$ & - & - \\
\hline Smoking & $1 \cdot 35$ & $0 \cdot 64$ & $2 \cdot 83$ & $1 \cdot 02$ & $0 \cdot 60$ & $1 \cdot 73$ \\
\hline $\begin{array}{l}\text { Duration of incarceration at time of TST } \\
\text { administration }>36 \text { months }\end{array}$ & $1 \cdot 00$ & - & - & $1 \cdot 00$ & - & - \\
\hline $\begin{array}{l}\text { Duration of incarceration at time of TST } \\
\text { administration } \leqslant 36 \text { months }\end{array}$ & $1 \cdot 66$ & $0 \cdot 54$ & $5 \cdot 09$ & $0 \cdot 99$ & $0 \cdot 61$ & $1 \cdot 59$ \\
\hline Age $>36$ years & $1 \cdot 00$ & - & - & $1 \cdot 00$ & - & - \\
\hline Age $\leqslant 35$ years & $1 \cdot 28$ & $0 \cdot 84$ & $1 \cdot 96$ & $1 \cdot 20$ & $0 \cdot 55$ & $2 \cdot 59$ \\
\hline No overweight ${ }^{\dagger}$ & $1 \cdot 00$ & - & - & $1 \cdot 00$ & - & - \\
\hline Overweight $^{\dagger}$ & $1 \cdot 15$ & $0 \cdot 72$ & $1 \cdot 84$ & $1 \cdot 61$ & $1 \cdot 05$ & $2 \cdot 47$ \\
\hline Prior incarceration & $0 \cdot 75$ & $0 \cdot 34$ & $1 \cdot 63$ & $0 \cdot 64$ & $0 \cdot 24$ & $1 \cdot 67$ \\
\hline
\end{tabular}

TB, tuberculosis; TST, tuberculin skin test; BCG, bacillus Calmette-Guérin vaccine.

* All positive TST converters were incarcerated in prison 1.

$\dagger$ Body mass index $\geqslant 25 \mathrm{~kg} / \mathrm{m}^{2}$.

Variables included in the model: age, contact with a prisoner with TB prior to TST administration, overweight, current place of incarceration, smoking, duration of incarceration at time of TST administration, BCG scar and prior incarceration.

order to identify one case of active TB among HIV-infected ranged between 10 and 61 and among household contacts between 14 and 64 [4] depending on whether the country or setting had a high, moderate, or low TB incidence. The same systematic review identified a much lower risk and therefore a larger NNS among prisoners [4].

Based on the findings in the prisons studied, we propose that the risk is higher among people entering prison with negative TST, representing a segment of prisoner population at exceptionally high risk for acquisition of $M$. tuberculosis infection; hence, targeted screening and follow-up over time is associated with a low NNS [4]. We believe that this approach may be useful in other high incidence prison settings.

Prisons have multiple socio-economic and environmental factors that enable TB transmission. Dara et al. reported that some factors that contribute to the transmission are: overcrowding, poor ventilation, lack of surveillance, case detection and contact tracing, inadequate treatment of infectious cases, and weak implementation of control measures [28]. In addition, population density has been associated with the risk of exposure; thereupon, the likelihood of one susceptible person being exposed to an infectious case increases with population density [29]. The documented relationship between population density and TST conversion indicate that crowded conditions facilitate TB transmission [9,30]. In fact, Stuckler et al. showed that when prisons have excessive growth in their population, it is necessary to put particular emphasis on controlling TB transmission. An increased number of prisoners is a determinant for $\mathrm{TB}$ and multi-drug-resistant $\mathrm{TB}$ prevalence and incidence [30].

In Eastern Europe and Central Asia, the increase in incarceration rates has been associated with up to $60 \%$ increase in TB and multi-drug-resistance rates in the community [31].

TB control requires efficient programs to identify new breaches according to the epidemiological situation in each country, considering their economic 
resources, in order to respond to the need of each population [32]. Albeit, the vast majority of prisons worldwide have not implemented programs for this situation. Vinkeles Melchers et al. showed that approximately $21 \%$ of those studies reflected the lack of healthcare programs in prisons [33], which allows for an easier transmission between inmates, prison workers, visitors, and general population [28,34].

This is a critical problem since outbreaks in prisons have been associated with the increase of TB in the community [30]. This scenario results in serious implications for public health programs, because the prisoners are commonly released and returned to the community [31] even before they have completed their treatment, and without follow-up appointments outside of the prison settings [30,31].

The main limitations of the study were that we could not follow all TST-negative prisoners; therefore, the incidence of TST could represent an underestimate. We reviewed the mandatory reporting system of public health diseases and did not find those prisoners among those diagnosed with active TB, and therefore believe our findings are representative. Another limitation is the fact that LTBI screening and treatment were not recommended for prisoners in Colombia at the time of the study, nor was there access to LTBI treatment. Study participants did not receive isoniazid and we could not evaluate the impact of this intervention.

Based on our findings, we recommend the inclusion of follow-up with TST among initially negative inmates, with a follow-up every year to detect new converters, and offer them LTBI treatment. The study illustrates the high risk of $\mathrm{TB}$ acquisition among initially uninfected inmates as well as a very high risk of development of active TB. This subgroup had a risk that is comparable or higher than most groups for which routine screening for LTBI 'should be performed' based on WHO guidelines, and the low NNS to identify LTBI or active disease suggest that this approach may be feasible, effective, and benefit the prison population as well as the community at large, even in resource-limited settings. The potential effect of a comprehensive TB control program that includes LTBI management in prison contributed to a $73 \%$ decrease in the TB incidence in New York State Department of Correctional Services [35]. Further follow-up and assessment of the impact of this proposed intervention (i.e. LTBI treatment or active TB treatment) on in-prison transmission and transmission to the community are necessary.

\section{ACKNOWLEDGEMENTS}

The authors thank to all the prisoners who accepted to participate in the study, to INPEC (Instituto Nacional Penitenciario y Carcelario de Colombia) and the Director of each prison and all personnel who are working there for their support to execute the study, and to the field team (Deny Sánchez and Maryluz Posada) for their great job during the study period. This work was supported by Colciencias (Colombian Administrative Department of Science, Technology and Innovation) and Universidad de Antioquia (Grant No. 111556934182). The funders had no role in study design, data collection and analysis, decision to publish, or preparation of the manuscript. The authors contributions follow the 4 criteria of authorship recommended by International Committee of Medical Journal Editors (ICMJE): Conception and design of the work: ZVR, LL, DM. Analysis and interpretation of data: ZVR, LL, YK. Drafting the article: ZVR, YK. Revising the paper critically for important intellectual content and final approval of the version to be published: all authors. Agreement to be accountable for all aspects of the work in ensuring that questions related to the accuracy or integrity of any part of the work are appropriately investigated and resolved: all authors.

\section{DECLARATION OF INTEREST}

None.

\section{ETHICAL STANDARDS}

The authors assert that all procedures contributing to this work comply with the ethical standards of the relevant national and institutional committees on human experimentation and with the Helsinki Declaration of 1975, as revised in 2013.

The study was approved from the Human Research Ethics Committee of the Facultad Nacional de Salud Pública and the Instituto Nacional Penitenciario y Carcelario. We obtained consent form in the presence of two witnesses, prisoners or family and friend (person out prison). We explained the objective and procedures of research, the first TST application by two steps, and the follow-up for 2 years to detect LTBI and that participation was voluntary. All prisoners that had respiratory symptoms were studied to rule out active TB by healthcare authorities. Those who were diagnosed with TB received anti-TB treatment. 
Because LTBI screening and treatment are not recommended for prisoners in Colombia at the time of the study, nor is there access to LTBI treatment, participants did not receive isoniazid. We advocate for access to LTBI screening and treatment for inmates, which has not yet been accepted or funded.

\section{REFERENCES}

1. Baussano I, et al. Tuberculosis incidence in prisons: a systematic review. PLoS Medicine 2010; 7: e1000381.

2. Rangaka MX, et al. Controlling the seedbeds of tuberculosis: diagnosis and treatment of tuberculosis infection. The Lancet 2015; 386: 2344-2353.

3. Getahun H, et al. Management of latent Mycobacterium tuberculosis infection: WHO guidelines for low tuberculosis burden countries. The European Respiratory Journal 2015; 46: 1563-1576.

4. WHO. WHO|Systematic Screening for Active Tuberculosis: Principles and Recommendations (http:// www.who.int/tb/tbscreening/en/). Accessed 29 August 2016.

5. Narasimhan P, et al. Risk factors for tuberculosis. Pulmonary Medicine 2013; 2013: 828939. doi:10.1155/ 2013/828939.

6. Al-Darraji HAA, Kamarulzaman A, Altice FL. Latent tuberculosis infection in a Malaysian prison: implications for a comprehensive integrated control program in prisons. BMC Public Health 2014; 14: 22.

7. Dara M, Acosta CD. Tuberculosis prevention and control in prisons: do we know enough? The International Journal of Tuberculosis and Lung Disease 2014; 18: 758-759.

8. Rueda $\mathbf{Z V}$, et al. High prevalence and risk factors associated with latent tuberculous infection in two Colombian prisons. The International Journal of Tuberculosis and Lung Disease 2014; 18: 1166-1171.

9. MacIntyre CR, et al. Impact of tuberculosis control measures and crowding on the incidence of tuberculous infection in Maryland prisons. Clinical Infectious Diseases 1997; 24: 1060-1067.

10. Lobato MN, Leary LS, Simone PM. Treatment for latent TB in correctional facilities: a challenge for TB elimination. American Journal of Preventive Medicine 2003; 24: 249-253.

11. Rueda $\mathbf{Z V}$, et al. High incidence of tuberculosis, low sensitivity of current diagnostic scheme and prolonged culture positivity in four Colombian prisons. A Cohort Study. PLoS ONE 2013; 8: e80592.

12. Menzies D. Interpretation of repeated tuberculin tests. Boosting, conversion, and reversion. American Journal of Respiratory and Critical Care Medicine 1999; 159: $15-21$.

13. Baussano I, et al. Tuberculosis among health care workers. Emerging Infectious Diseases 2011; 17: 488-494.

14. Kolappan C, et al. Estimation of annual risk of tuberculosis infection (ARTI) among children aged 1-9 years in the south zone of India. The International
Journal of Tuberculosis and Lung Disease 2004; 8: 418-423.

15. Lebina L, et al. Latent tuberculous infection in schoolchildren and contact tracing in Matlosana, North West Province, South Africa. The International Journal of Tuberculosis and Lung Disease 2015; 19: 1290-1292.

16. Shanaube K, et al. Annual risk of tuberculous infection using different methods in communities with a high prevalence of TB and HIV in Zambia and South Africa. PLOS ONE 2009; 4: e7749.

17. H Masoumi Asl, Alborzi A, Pourabbas B. Prevalence of latent tuberculosis infection in low-risk children using tuberculin skin test: a study in shiraz. Tehran University Medical Journal (TUMJ) 2012; 70: 423-429.

18. Adjoh K, Wateba IM, Tidjani O. Prevalence of latent TB infection in HIV infected persons in the Sylvanus Olympio teaching hospital of Lomé. International Journal of Mycobacteriology 2013; 2: 26-28.

19. Almeida LM, et al. Use of purified protein derivative to assess the risk of infection in children in close contact with adults with tuberculosis in a population with high Calmette-Guérin bacillus coverage. The Pediatric Infectious Disease Journal 2001; 20: 1061-1065.

20. Byun JM, et al. The risk of tuberculosis in Korean patients with inflammatory bowel disease receiving tumor necrosis factor- $\alpha$ blockers. Journal of Korean Medical Science 2015; 30: 173-179.

21. Shu C-C, et al. Comparison of the prevalence of latent tuberculosis infection among non-dialysis patients with severe chronic kidney disease, patients receiving dialysis, and the dialysis-unit staff: a cross-sectional study. PLoS ONE 2015; 10: e0124104.

22. Joshi R, et al. Tuberculosis among health-care workers in low- and middle-income countries: a systematic review. PLoS Med 2006; 3: e494.

23. Margolis B, et al. Prevalence of tuberculosis symptoms and latent tuberculous infection among prisoners in northeastern Malaysia. The International Journal of Tuberculosis and Lung Disease 2013; 17: 1538-1544.

24. Leow MKS, et al. Latent tuberculosis in patients with diabetes mellitus: prevalence, progression and public health implications. Experimental and Clinical Endocrinology \& Diabetes 2014; 122: 528-532.

25. Martínez-Aguilar G, et al. Associated risk factors for latent tuberculosis infection in subjects with diabetes. Archives of Medical Research 2015; 46: 221-227.

26. Pealing $\mathbf{L}$, et al. Risk of tuberculosis in patients with diabetes: population based cohort study using the UK Clinical Practice Research Datalink. BMC Medicine 2015; 13: 135.

27. Sia IG, Wieland ML. Current concepts in the management of tuberculosis. Mayo Clinic Proceedings 2011; 86: $348-361$.

28. Dara M, et al. Tuberculosis control in prisons: current situation and research gaps. International Journal of Infectious Diseases 2015; 32: 111-117.

29. Rieder H. Epidemiologic Basis of Tuberculosis Control. Primera Ed. Paris. Unión Internacional contra la 
tuberculosis y enfermedades respiratorias. Paris, UK: International Union Against Tuberculosis and Lung Disease, 1999.

30. Stuckler D, et al. Mass incarceration can explain population increases in TB and multidrug-resistant TB in European and central Asian countries. Proceedings of the National Academy of Sciences of the United States of America 2008; 105: 1328013285.

31. Winetsky DE, et al. Screening and rapid molecular diagnosis of tuberculosis in prisons in Russia and Eastern Europe: a cost-effectiveness analysis. PLoS Medicine 2012; 9: e1001348.
32. Millet J-P, et al. Factors that influence current tuberculosis epidemiology. European Spine Journal 2013; 22: 539-548.

33. Vinkeles Melchers NVS, et al. State of affairs of tuberculosis in prison facilities: a systematic review of screening practices and recommendations for best TB control. PLOS ONE 2013; 8: e53644.

34. Öngen G, et al. Pulmonary tuberculosis incidence in Turkish prisons: importance of screening and case finding strategies. Tüberküloz Ve Toraks 2013; 61: 21-27.

35. Klopf LC. Tuberculosis control in the New York State Department of Correctional Services: a case management approach. American Journal of Infection Control 1998; 26: 534-537. 